\title{
Acceptance Speech for the 1993 Clarke Award
}

\section{YOUIXIJE. 7.HANG ${ }^{*}$}

Thank you, Ed (and Dave, as it was then), for the kind words. I am deeply honored to receive this unexpected award from the Geochemical Society and overwhelmed to have been placed in the company of Clarke medalists, many of whom I know and admire. Two of them, Dave Walker and Ed Stolper, have had a profound influence on my career. It humbles me to think about so many worthy peers and to know that even some great minds of geochemistry have not received this award.

It is indeed a privilege and honor just to do sciences, not only because you are paid for doing what interests you, but also because you are not restricted in the choices of research projects. I have certainly enjoyed this freedom and have worked on a diverse variety of problems related to diffusion in silicate melts, glasses and minerals, the degassing history of the Earth, island arc petrogenesis, and volcanic eruptions.

The progress of science is always built upon previous work. This is especially true in my case. Let me give you an example. Water diffusion in silicate melts and glasses is an interesting problem that has attracted many workers. I was especially interested in the project because it was the first diffusion problem in which the concentration of the several species involved in the diffusion of a component can be measured directly, and hence it provides an ideal case to study the role of speciation during diffusion. When I started working on this, much had already becn lcarned about watcr in silicate melts and glasses, and therefore the time was ripe to gain a deeper understanding of this problem. For example, the diffusivity of water in rhyolitic melts had been found by Shaw, Jambon, Karsten, and Delaney, and other workers to increase with total water concentration. The work of Stolper and his group, including Newman, Silver, and others using infrared spectroscopy had established the presence of two species of dissolved water, $\mathrm{OH}$ groups and $\mathrm{H}_{2} \mathrm{O}$ molecules. They had also calibrated the infrared technique so that measuring the concentration of the two species in a small area could be done in a routine manner. We knew by then that $\mathrm{OH}$ groups and $\mathrm{H}_{2} \mathrm{O}$ molecules interconvert in the structure and that the ratio of molecular $\mathrm{H}_{2} \mathrm{O}$ to $\mathrm{OH}$ groups increases with total water concentration. The early work of Doremus and the more recent work of Wasserburg had proposed that molecular $\mathrm{H}_{2} \mathrm{O}$ is the diffusing species for water diffusion in silicate melts and glasses, even though some other workers disagreed. It was then that I arrived at Caltech to study water diffusion and to attack the more general problem of the role of speciation during diffusion. From our experimental data and theoretical analysis, Ed Stolper, Jerry Wasserburg, and I were able to show that molecular $\mathrm{H}_{2} \mathrm{O}$ is the diffusing species for water diffusion in our rhyolitic glasses. We were also able to

\footnotetext{
* The University of Michigan, Department of Gcological Sciences, Ann Arbor, MI 48109, USA.
}

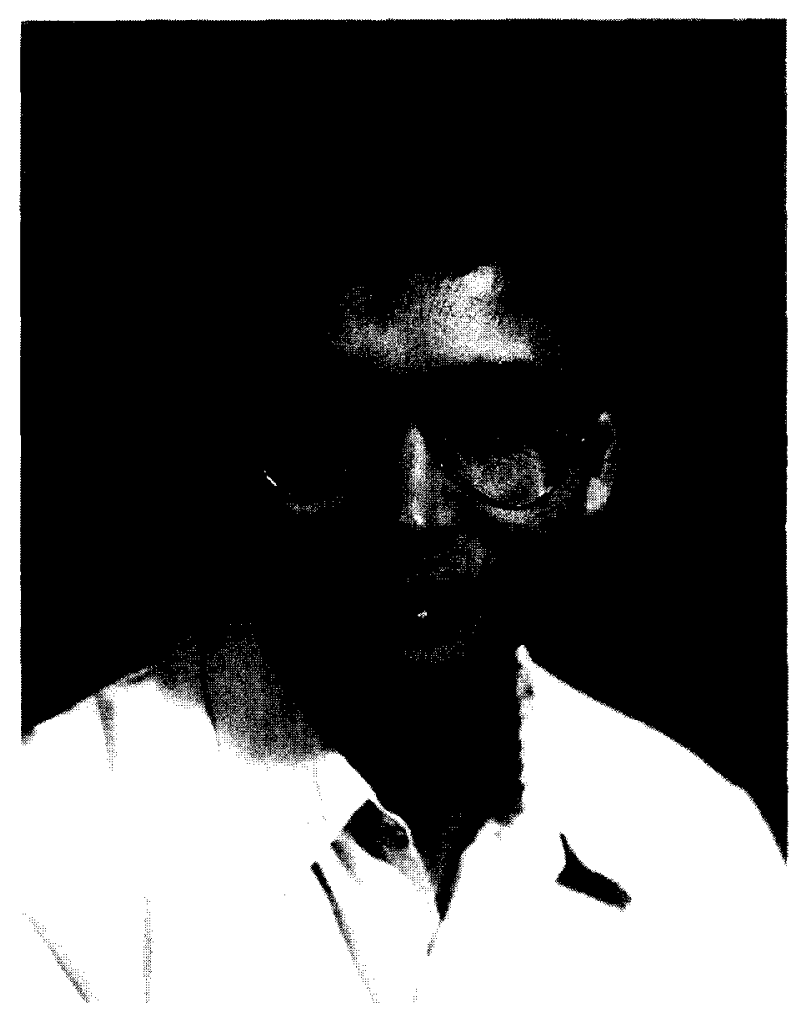

apply this idea to the diffusion of oxygen into minerals under hydrothermal conditions.

Likewise, my work with Dave Walker and Chip Lesher on the multicomponent diffusion in natural silicate melts, and my recent work on a modified effective binary diffusion model to treat uphill diffusion, are built upon the work of Watson, Lasaga, Ryerson, Lesher, and others. Time would not permit me to discuss in detail their contributions, but the importance of their work must be recognized. I must say that this medal belongs as much to all of them as it does to me.

One of the great joys of receiving this award is to give public thanks to people who helped me over the years. As I look back, I realize more and more how fortunate I have been. First I thank my father, Zaiyi Zhang, and my mother, Dezhen $\mathrm{Wu}$, for their never-ending support and encouragement. During the Cultural Revolution in China, when I was a tecnager, my father cncouraged me to continue school even though my family was poor and sometimes I had to go to school without breakfast. When I was hesitating whether to go to the Department of Geology at Peking University, it was my father who persuaded me to go. I would also like to thank those (some were my teachers, some were my friends, and some of them I knew little) who helped me unsolicitedly and unexpectedly during the difficult times in my life and career. 
I was fortunate to have attended Peking University, where I not only obtained a solid science background, but also benefited tremendously from the academic environment and the free spirit created by the professors and students. I hope that this free spirit will continue.

As a graduate student at Lamont-Doherty Gcological Observatory and Department of Geological Sciences of Columbia University, I enjoyed the freedom and opportunity offered by one of the most exciting petrology/geochemistry groups in the world newly created by Charlie Langmuir, Dave Walker, and Alan Zindler. They allowed me almost complete freedom in selecting and carrying out research projects, but whenever I needed them, they were there to help. I took advantage of the opportunities offered by them and indeed worked with and benefited from all of them (I may have been the only student who co-authored papers with all of them). Among many other things they taught me, Dave Walker very patiently taught me the trade secrets of experimental petrology, and even how to shoot slides. I confess that I had never even tightened a nut before I started to be an experimentalist. Without Dave's patience and help, I would not be an experimentalist today. I must confess again that I will never be as good an experimentalist as Dave. At Lamont, I also benefited from Chip Lesher and Jim Rubenstone, who were a constant source of not only technical help, but also sound advice and encouragement. Strong interactions among the students were also a great help to me.

I received an important part of my education during my postdoctoral years at Caltech. I learned a great deal from two of the greatest minds in geochemistry, Ed Stolper and Jerry Wasserburg. Their ability to comprehend and perceive both the big picture and the minutest details of a problem always amazed me. I was also helped by the incredibly talented students and research fellows at Caltech. Being a part of that team was a great opportunity.

At the Department of Geological Sciences of the University of Michigan, I have received the enthusiastic encouragement and support of the entire faculty. They helped me with their experience in teaching and in how to write proposals. They are also the testing ground whenever I have some crazy or not so crazy idea. My friendships and interactions with Eric Essene, Mike Gurnis, Alex Halliday, Becky Lange, Sam Mukasa, Jim O'Neil, Henry Pollack, and Bruce Wilkinson have been most helpful.

As an outsider coming from China ten years ago and as the first Chinese to receive this award, I especially appreciate the generosity, kindness, friendship, open-mindedness, enthusiasm, and the free spirit of the American academia. I hope that this fine American tradition will not abate, and that America will always welcome outsiders. I can only assure you of my sincere friendship and I hope to repay by emulating what I have learned from you.

Last of all, I want to thank my wife, Zhengjiu, for her support and encouragement over many years.

I sincerely appreciate receiving this award and hope to live up to the reputations established by past recipients. Thank you. 